\title{
Investigation of a Self-Excited Pulsed Water Jet Slotting for Coal Roadway Driving
}

\author{
Jianguo Zhang ${ }^{1, a}$, Jinjing Zhang ${ }^{1, b}$ and Zhe Zhou ${ }^{2, c}$ \\ ${ }^{1}$ State Key Laboratory of Coking Coal Exploitation and Comprehensive Utilization, Pingdingshan \\ 467000, China; \\ ${ }^{2}$ State Key Laboratory of Coal Mine Disaster Dynamics and Control, Chongqing University, \\ Chongqing 400044, China. \\ akjx7043@163.com, ${ }^{b} 573052853 @ q q . c o m,{ }^{c}$ cquzhouzhe@163.com
}

Keywords: pulsed water jet; hydraulic slotting seam; FLAC3D; coal roadway driving; outburst prevention

\begin{abstract}
Advance borehole is commonly used to prevent outburst in driving working face, while the influence scope of drilling is limited in deep mining, resulting in large drilling construction and taking very long construction time. A slotting technology by using self-excited oscillation pulsed water jets is proposed to solve this problem. Pulsed jet slotting can improve the pressure relief scope of borehole and increase the permeability of coal seam and gas desorption rate, which will shorten the period of gas excavation and driving roadway. This work use FLAC3D to research the influence of pressure relief by pulsed water jet slotting on the distribution of coal stress, and the influence scope is acquired combine field experiment. Since the pressure relief radius is enough to cover adjacent borehole, cross slotting arrangement is proposed to reduce slotting construction. Application at Pingdingshan No.5 coal mine shows that the pressure relief radius of one borehole after slotted can be more than $2.5 \mathrm{~m}$ in coal seam. The total gas drainage amount of driving working face was increased by 3.37 times, which would provide safety guarantee for rapid driving in coal seam. The monthly driving rate of coal roadway was improved by one time.
\end{abstract}

\section{Introduction}

With the increase of coal mining depth, ground stress and gas pressure in coal seam gradually increase, and the permeability of coal seam is smaller and smaller [1-2]. The traditional gas control method is drilling drainage boreholes in coal seam to drain gas [3-4]. However, this method will be inefficient when used in deep mining because the effect of pressure relief and effective impact range of boreholes will decrease and the quantity demanded of borehole will increase, increasing the drilling construction [5].

$\mathrm{Li}$ and $\mathrm{Lu}$ et al. put forward a way by using pulsed water jet drilling and slotting coal seam to improve the permeability of soft coal seam and the gas extraction efficiency [6]. Pulsed water jet can make an impact and erosion effect on coal seam, and the impact load can effectively break coal to increase the crack rate and connectivity of coal to increase the permeability [7-8]. The technology of pulsed jet slotting has been applied in rock cross-cut coal uncovering in Chongqing Fengchun coal mine. The extraction radius of gas drainage borehole after slotted can be more than $1.5 \mathrm{~m}$, increasing the ability of gas desorption from coal seam. The construction period was shortened more than 70d, achieving better gas pressure relief effect [9].

However, in the process of coal roadway driving, boreholes are all drilled down the seam, which is different from cross layer borehole during cross-cut coal uncovering. There are just a few meters in coal for cross layer borehole, so once slotting is enough to release pressure in coal. Bedding borehole is all in coal, so multiple slotting is necessary for one borehole. Therefore, the slotting spacing and drilling spacing are two important parameters to determine the drilling and slotting scheme.

In this paper, by means of FLAC3D simulation, the influence of pulsed water jet slotting on the stress field of driving face in coal roadway was analyzed, and the arrangement of slotting boreholes 
was optimized. Moreover, the devices of pulsed water jet slotting system were transported to the site to conduct field tests, and the pressure relief effect of slotting was examined through measuring the extraction effect and the index of outburst prevention.

\section{Application principle of self-excited oscillation pulsed water jet}

Characteristics of self-excited oscillation pulsed water jet. Self-excited oscillation pulsed water jet is a new type of high efficient jet and developed by the principle of fluid mechanics and elasticity mechanics [10]. By closed loop feedback and magnifying vorticity disturbance on jet boundary layer, continuous water jet will become pressure pulsation impingement water jet, and its impact force is $1.5 \sim 2.5$ times of that of continuous water jet, greatly improving the efficiency of rock breaking [11-12].

Self-excited oscillation pulsed water jet has the characteristics of pulsed jet and cavitating jet [13]. In addition, the generation devices have simple structures, good sealing property and high reliability.

The slotting principle of pulsed water jet. During pulsed jet slotting, the impact and oscillation effect of pulsed jet cause changes on the stress field of coal and stress redistribution, and the effective volume stress of coal seam will be released and coal seam pressure will be released fully to promote gas desorption. Besides, the acoustic shock effect of pulsed jet generates stress wave which causes repeated compression and tension of coal to form fractures to further promote gas desorption.

The increasing exposure area of coal after implementing slotting can be considered as a local pressure relief protective layer. A larger range of fissure zone forms in the surrounding coal, which significantly increases aisles for gas migration to improve gas extraction rate at the beginning of gas extraction.

\section{The pressure relief effect of pulsed jet slotting and process optimization}

Analysis on pressure relief scope of slotting. In order to research the pressure relief scope of pulsed jet slotting in coal seam, FLAC3D was used to simulate. The compared simulation is only drainage borehole model without slotting. In accordance with the coal seam occurrence condition of Pingdingshan No.5 mine test area, numerical model was established. The model size is $15 \mathrm{~m}$ $\times 15 \mathrm{~m} \times 15 \mathrm{~m}$, and the rock mass parameters assignment is shown in table 1 . The distance between two drainage boreholes center is $2.5 \mathrm{~m}$; The burial depth of coal seam is $400 \mathrm{~m}$; Slotting depth is $1.0 \mathrm{~m}$ and slotting width is $0.05 \mathrm{~m}$.

Table 1 The rock mass parameters assignment table

\begin{tabular}{ccccccc}
\hline Lithology & $\begin{array}{c}\text { Thickness } \\
(\mathrm{m})\end{array}$ & $\begin{array}{c}\text { Shear } \\
\text { modulus } \\
(\mathrm{GPa})\end{array}$ & $\begin{array}{c}\text { Bulk } \\
\text { modulus } \\
(\mathrm{GPa})\end{array}$ & $\begin{array}{c}\text { Cohesion } \\
(\mathrm{MPa})\end{array}$ & $\begin{array}{c}\text { Anelasticity } \\
\left({ }^{\circ}\right)\end{array}$ & $\begin{array}{c}\text { Tensile } \\
\text { strength } \\
(\mathrm{MPa})\end{array}$ \\
\hline Sandy mud & 5.5 & 1.14 & 1.73 & 3 & 24 & 0.7 \\
Coal & 4 & 0.44 & 1.43 & 1 & 25 & 0.03 \\
Mudstone & 1 & 0.53 & 1.86 & 2.7 & 30 & 0.5 \\
Sandy mud & 4.5 & 1.14 & 1.73 & 3 & 24 & 0.7 \\
\hline
\end{tabular}

Simulation results are shown in figure $1 \mathrm{a}$ is the stress distribution on the $\mathrm{X}$ direction and $1 \mathrm{~b}$ is the stress distribution on the Y direction. The comparison of pressure relief volume between slotting and no slotting model is shown in table 2. The effective pressure relief radius of slotting can reach $2.5 \mathrm{~m}$. On the $\mathrm{X}$ direction, the influence scope of slotting hole increases and can reach adjacent borehole. On the $\mathrm{Y}$ and $\mathrm{Z}$ directions, the pressure relief scope changes are not big but can effectively cover adjacent borehole. Therefore, when two boreholes space is less than the effective influence radius of a single slotting borehole, slotting can be conducted in only one hole to achieve pressure relief effect, reducing the construction. 


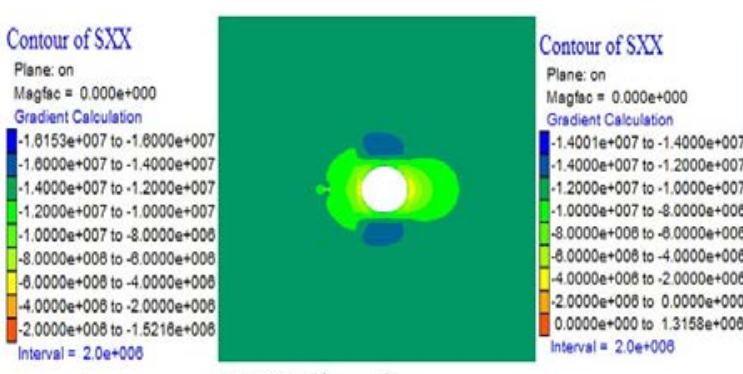

(a) $\mathrm{X}$ direction

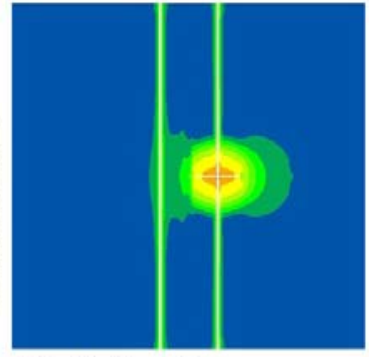

(b) $\mathrm{Y}$ direction

Fig. 1 Stress nephogram of slotting model

Table 2 The volume of pressure relief area of slotting model

\begin{tabular}{ccccc}
\hline Model & $\begin{array}{c}\text { The volume of } \\
\text { pressure relief on } \\
\text { the X direction }\left(\mathrm{m}^{3}\right)\end{array}$ & $\begin{array}{c}\text { The volume of } \\
\text { pressure relief on } \\
\text { the Y direction }\left(\mathrm{m}^{3}\right)\end{array}$ & $\begin{array}{c}\text { The volume of } \\
\text { pressure relief on } \\
\text { the Z direction }\left(\mathrm{m}^{3}\right)\end{array}$ & $\begin{array}{c}\text { Plastic zone volume } \\
\left(\mathrm{m}^{3}\right)\end{array}$ \\
\hline $\begin{array}{c}\text { Only drainage } \\
\text { borehole model } \\
\begin{array}{c}\text { Borehole and } \\
\text { slotting model }\end{array}\end{array}$ & 23.125 & 19.238 & 20.632 & 21.673 \\
\hline
\end{tabular}

The stress field variation of cross slotting arrangement. Because the pressure relief scope of slotting is wide enough to cover adjacent borehole, there is no need to slot at the same location for adjacent boreholes. Therefore, this work proposes the arrangement of cross slotting. As shown in Figure 2, slots for adjacent boreholes are staggered, and the stagger distance is half of the slotting space for a single borehole. Using this arrangement, the construction can be reduced and the same pressure relief effect can be achieved.

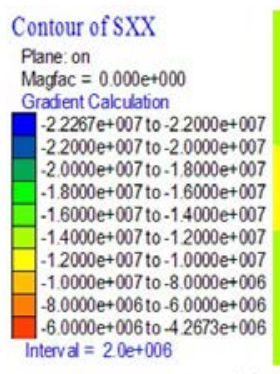

(a) $\mathrm{X}$ direction

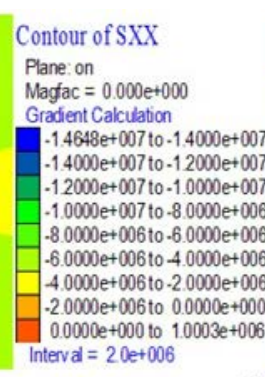

(b) Y direction

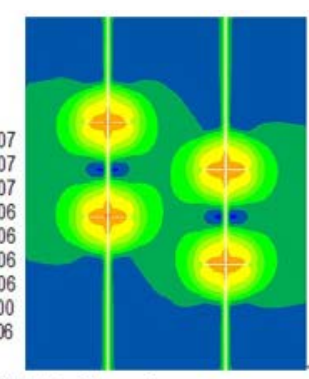

Fig. 2 Stress nephogram of cross slotting model

According to cross slotting process, model was built. In the model, the distance of two adjacent boreholes center is $5 \mathrm{~m}$. The slotting space of a single borehole is $4 \mathrm{~m}$, so the stagger slot distance for adjacent boreholes is $2 \mathrm{~m}$ on the $\mathrm{Y}$ direction. Calculation results are shown in figure 2, and $2 \mathrm{a}$ is the stress distribution on the $\mathrm{X}$ direction and $2 \mathrm{~b}$ is the stress distribution on the $\mathrm{Y}$ direction. The comparison with a single slot model pressure relief volume is shown in table 3 . The pressure relief volume of cross slotting is obviously bigger than that of single borehole, and the mutual influence between slots avoids the pressure relief shadow area. Therefore, cross slotting is a kind of reasonable and effective pulsed jet slotting arrangement for driving working face in coal roadway.

Table 3 The volume of pressure relief area of cross slotting model

\begin{tabular}{ccccc}
\hline Model & $\begin{array}{c}\text { The volume of } \\
\text { pressure relief on } \\
\text { the X direction }\left(\mathrm{m}^{3}\right)\end{array}$ & $\begin{array}{c}\text { The volume of } \\
\text { pressure relief on } \\
\text { the Y direction }\left(\mathrm{m}^{3}\right)\end{array}$ & $\begin{array}{c}\text { The volume of } \\
\text { pressure relief on } \\
\text { the } \mathrm{Z} \text { direction }\left(\mathrm{m}^{3}\right)\end{array}$ & $\begin{array}{c}\text { Plastic zone volume } \\
\left(\mathrm{m}^{3}\right)\end{array}$ \\
\hline $\begin{array}{c}\text { Single hole groove } \\
\text { model } \\
\begin{array}{c}\text { Multiple hole } \\
\text { groove model }\end{array}\end{array}$ & 23.125 & 19.238 & 20.632 & 21.673 \\
\hline
\end{tabular}

\section{The implementation scheme of pulsed jet slotting}

The result of numerical simulation shows the pressure relief radius of slotting can reach $2.5 \mathrm{~m}$. A site test of pulsed water jet slotting was carried out to verify the accuracy of numerical simulation and acquire the measured pressure relief radius. Accordingly, the space of borehole bottom can be 
confirmed to determine the drilling arrangement plans, and the implementation scheme of slotting for field application can be made up.

Gas geological conditions of experimental site. The test site of pressure relief and elimination outburst by pulsed jet slotting is 22302 intake airflow roadway in Pingdingshan No.5 mine. The coal thickness at driving working face is $1.2 \sim 4.0 \mathrm{~m}$ and average thickness is $2.8 \mathrm{~m}$. The dip angle of coal seam is $12 \sim 26^{\circ}$ and average angle is $15^{\circ}$. The firmness coefficient of coal is 0.3 . The gas pressure of coal seam is $1.7 \mathrm{MPa}$ and gas content is $17.4 \mathrm{~m}^{3} / \mathrm{t}$ having outburst risk.

Experimental equipment and connection. By drilling boreholes to drain gas traditionally, the original equipment mainly include drilling machine, emulsion pump, drill pipe and water delivery equipped in underground coal mine. When using pulsed water jet slotting measures, we utilize the original devices as much as possible to operate conveniently. There are some new devices needed to add into the system, including the automatic switching type slotting machine, high pressure water sealing device, high pressure sealing spiral drill pipe, high pressure rubber hose, quick connector and other necessary sealing and connection parts, as shown in figure 3.

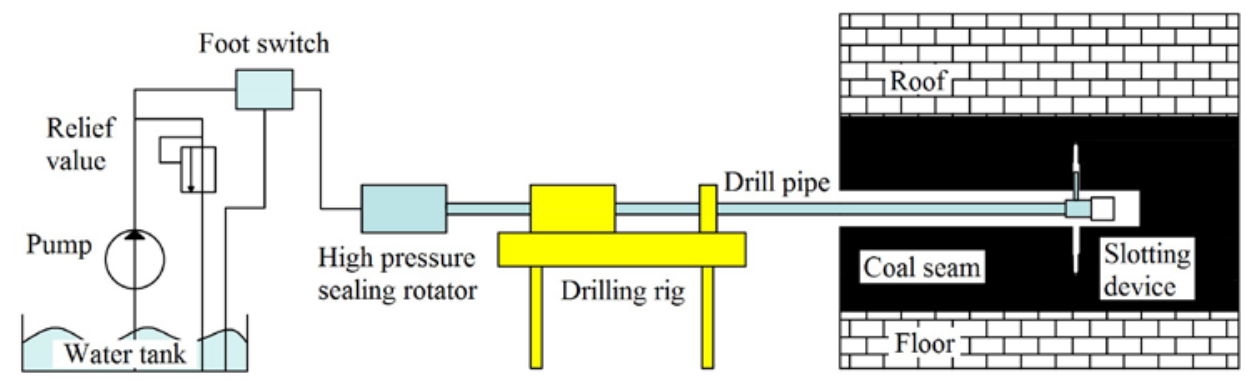

Fig. 3 The schematic diagram of slotting in 22302 intake airflow roadway

The effective pressure relief radius of slotting. This experiment used the method of borehole gas flow to determine the effective pressure relief radius of slotting. The holes arrangement is shown in figure 4. The number of hole is seven, one slotting hole and six observation holes. Slotting hole and observation holes were placed in 30m 40m in 22302 intake airflow roadway. The distance of observation holes and slotting hole is $0.5 \mathrm{~m}, 1 \mathrm{~m}, 1.5 \mathrm{~m}, 2 \mathrm{~m}$ and $2.5 \mathrm{~m}$ respectively. After slotting hole slotted, if the gas flow of observation hole increases by more than $10 \%$, observation hole can be thought of within effective radius of slotting.

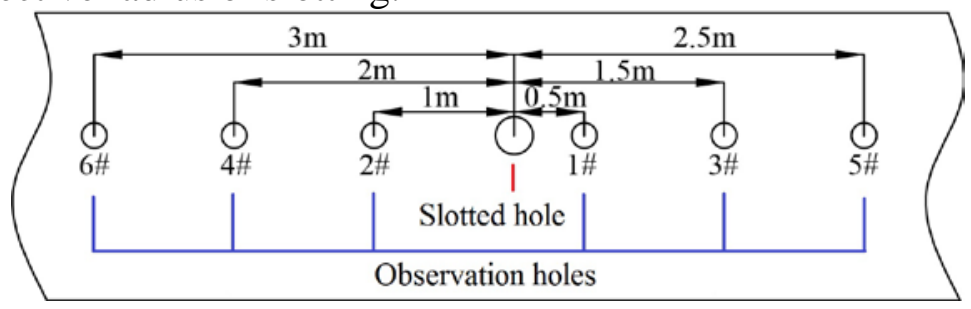

Fig. 4 Profile map of holes arrangement

Observation holes need to be sealed in time after drilled. Slotting holes after completing drilling process need to be measured gas flow before slotting, afterwards conducting hydraulic slotting and then measuring the observation holes gas flow rate every 2 minutes. The measurement results are shown in figure 5 . For $1 \#$, 2\#, 3\#, 4\#, $5 \#$ holes, the gas flow respectively increases $85 \%, 80 \%$, 55\%, $31 \%, 66 \%$ after slotting, all more than $10 \%$. The gas flow of $6 \#$ observation hole almost has no change, so the effective radius of pulsed jet slotting can be considered as $2.5 \mathrm{~m}$. 


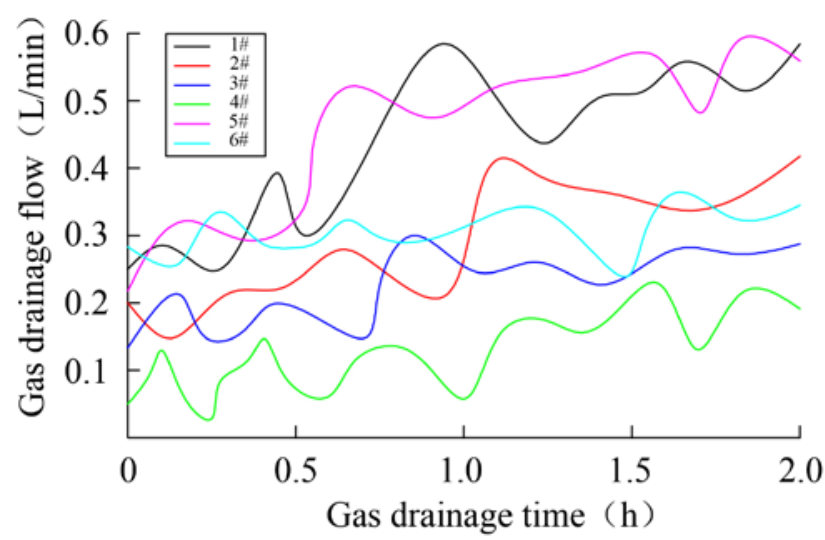

Fig. 5 The gas flow curve for observation holes

In accordance with regulations on outburst prevention of driving working face in coal roadway in the "Provisions on Prevention of Coal and Gas Outburst", the scope of control during driving should be determined combined with the site conditions. The drilling distance along the driving direction in coal seam roadway is $60 \mathrm{~m}$. The reserved advanced distance should exceed $20 \mathrm{~m}$. The drilling control scope up and down sides of roadway on the direction perpendicular to driving direction should exceed $15 \mathrm{~m}$. The results of numerical simulation and field tests show that pressure relief radius after pulsed jet slotting in coal seam can reach $2.5 \sim 3 \mathrm{~m}$. Considering the guarantee of safety margin, the distance of boreholes bottom is determined as $5 \mathrm{~m}$. Boreholes arrangement is shown in figure 6

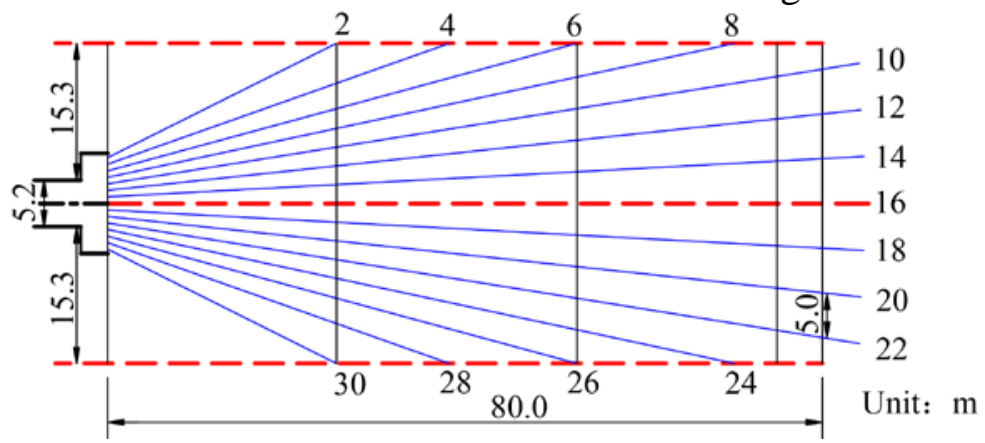

Fig. 6 Profile map of drilling boreholes arrangement

\section{The application effect of slotting for pressure relief}

The effect of extraction. The driving face in 22302 return airway was implemented only drainage borehole extraction measures without pulsed jet slotting, and it is a comparison to 22302 intake airflow roadway to investigate the influence of slotting on the extraction effect. Taking daily pure gas drainage amount as the check index, the comparison result is shown in figure 7.

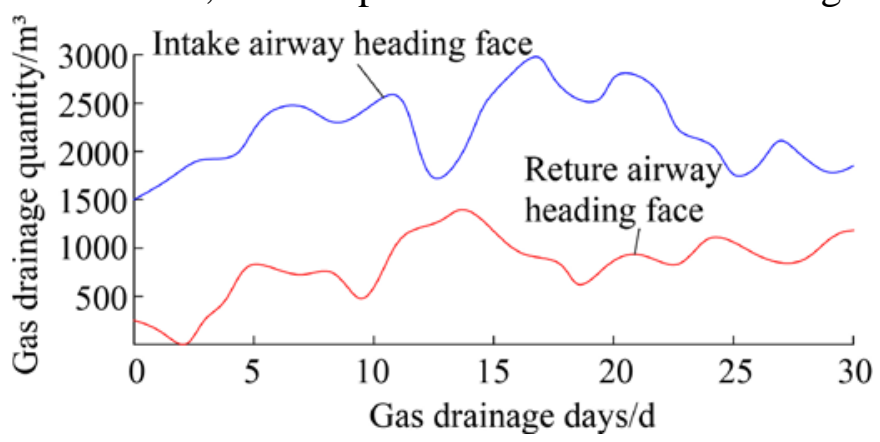

Fig. 7 The gas drainage amount comparison of 22302 return airway and intake airflow roadway

The figure 7 shows that the daily pure gas drainage amount of driving face in 22302 intake airflow roadway significantly higher than that of driving face in return airway. The monthly cumulative gas extraction amount of driving face in 22302 intake airflow roadway is $79506 \mathrm{~m}^{3}$, and average daily amount is $2650.2 \mathrm{~m}^{3}$. The monthly cumulative gas extraction amount for 22302 return airway is 
$23588 \mathrm{~m}^{3}$, and average daily amount is only $786.2 \mathrm{~m}^{3}$. The monthly extraction amount for 22302 intake airflow roadway is 3.37 times of that for 22302 return airway. The time requires for extraction for 22302 intake airflow roadway is $41 \mathrm{~d}$, and that for return airway is $90 \mathrm{~d}$, greatly improving the extraction efficiency. Therefore, pulsed jet slotting technology can make coal release gas pressure effectively and increase the permeability of coal seam.

Residual gas content and pressure. After extraction for $41 \mathrm{~d}$ from pulsed jet slotting, three kinds of coal samples were respectively taken from places of $20 \mathrm{~m}, 50 \mathrm{~m}$ and $80 \mathrm{~m}$ distance from the driving face. The residual gas content and pressure were determined by underground fixed-point desorption, normal pressure desorption in laboratory, crushing desorption and laboratory industrial analysis. Ultimately, measured residual gas content and pressure of samples at depth of $20 \mathrm{~m}$ are $2.3498 \mathrm{~m}^{3} / \mathrm{t}$ and $0.21 \mathrm{MPa}$ respectively. The content and pressure of samples at depth of $50 \mathrm{~m}$ are $3.1269 \mathrm{~m}^{3} / \mathrm{t}$ and $0.25 \mathrm{MPa}$, and that of $80 \mathrm{~m}$ are $3.2881 \mathrm{~m}^{3} / \mathrm{t}$ and $0.36 \mathrm{MPa}$ respectively. These values are all less than the critical value of $8 \mathrm{~m}^{3} / \mathrm{t}$ and $0.74 \mathrm{MPa}$, judged to be no outburst danger.

After the beginning of roadway driving, tests of outburst prevention index were carried out for nine times. The measured values of $\mathrm{q}$ are $1.4 \sim 2.4 \mathrm{~L} / \mathrm{min}$, and the values of $\mathrm{S}$ are $2.7 \sim 3.2 \mathrm{~kg} / \mathrm{m}$. All values are less than the critical value of $5 \mathrm{~L} / \mathrm{min}$ and $6 \mathrm{~kg} / \mathrm{m}$, judged to be no outburst danger. There was no phenomenon of gas exceeding the limit during the driving.

The outburst elimination effect of pulsed jet slotting technology is ideal, effectively reducing the gas content and pressure in coal seam.

The speed of driving in coal roadway. Adopting pulsed jet slotting technology in coal seam can release gas pressure obviously, improve the permeability of coal seam and the effect of extraction, and effectively control gas content and pressure in coal seam. There was no instability phenomenon in the process of local drilling to test effect, and inspection index is not overweight. The monthly cumulative driving penetration of 22302 intake airflow roadway is $106.2 \mathrm{~m}$ after implementing pulsed jet slotting measures, but that of return airway without implementing slotting is only $53.6 \mathrm{~m}$. The driving speed is increased nearly 1 time.

\section{Conclusion}

Pulsed jet slotting can make the coal seam release pressure effectively, and the influence radius is greater than $2.5 \mathrm{~m}$. The cross slotting is a good arrangement for pressure relief during driving in coal roadway. Pulsed jet slotting technology has been applied in 22302 intake airflow roadway in Pingdingshan No.5 mine, and the effect of outburst elimination was obvious. The gas drainage amount at driving working face increased by 3.37 times. The extraction time reduced from $90 \mathrm{~d}$ to $41 \mathrm{~d}$. Residual gas content in coal seam increased to $3.28 \mathrm{~m}^{3} / \mathrm{t}$ below the critical value of $8 \mathrm{~m}^{3} / \mathrm{t}$ in the "Provisions on Prevention of Coal and Gas Outburst". The Monthly accumulative penetration driving in coal roadway increased from $53.6 \mathrm{~m}$ to $106.2 \mathrm{~m}$. The Pingdingshan No.5 mine is a typical outburst mine, so the good application of pulsed jet slotting technology in this mine can become the reference for the popularization and application in other mines.

\section{Acknowledgments}

This study was financially supported by the National Natural Science Foundation of China (NSFC) under Grant No. 51374258 and No. 51504046, Program for Changjiang Scholars and Innovative Research Team in University of China under Grant No. IRT13043.

Corresponding author: Zhe Zhou. E-mail address: cquzhouzhe@163.com.

\section{References}

[1] D. Chen, Z. J. Pan, J. S. Liu, An improved relative permeability model for coal reservoirs, Int. J. Coal. Geol. 109 (2013) 45-57. 
[2] Z. J. Pan, L. D. Connell, Modelling permeability for coal reservoirs: A review of analytical models and testing data, Int. J. Coal. Geol. 92 (2012) 1-44.

[3] L. Wang, Y. P. Cheng, C. Xu, F. H. An, K. Jin, X. L. Zhang, The controlling effect of thick-hard igneous rock on pressure relief gas drainage and dynamic disasters in outburst coal seams, Nat. Hazards. 66 (2013) 1221-1241.

[4] C. Liu, F. B. Zhou, K. K. Yang, X. Xiao, Y. K. Liu, Failure analysis of borehole liners in soft coal seam for gas drainage, Eng. Fail. Anal. 42 (2014) 274-283.

[5] Y. Y. Lu, Z. Zhou, Z. L. Ge, X. W. Zhang, Q. Li, Research on and design of a self-propelled nozzle for the tree-type drilling technique in underground coal mines, Energies. 8 (2015) $14260-14271$.

[6] Y. Y. Lu, Y. Liu, X. H. Li, Y. Kang, A new method of drilling long boreholes in low permeability coal by improving its permeability, Int. J. Coal. Geol. 84 (2010) 94-102.

[7] X. H. Li, D. P. Zhou, Y. Y. Lu, Y. Kang, Y. Zhao, X. C. Wang, Dynamic effects of high-pressure pulsed water jet in low-permeability coal seams, J. Coal. Sci. Eng. (China) 15 (2009) 284-288.

[8] S. Dehkhoda, M. Hood, H. Alehossein, D. Buttsworth, Analytical and experimental study of pressure dynamics in a pulsed water jet device, Flow. Turbul. Combust. 89 (2012) 97-119.

[9] Y. Y. Lu, Z. L. Ge, X. H. Li, J. F. Chen, Y. Liu, Investigation of a self-excited pulsed water jet for rock cross-cutting to uncover coal, J. China. Uni. Min. Tech. 36 (2010) 55-58.

[10]M. Hood, S. Dehkhoda, An experimental study of surface and sub-surface damage in pulsed water-jet breakage of rocks, Int. J. Rock. Mech. Min. Sci. 63 (2013) 138-147.

[11]S. Dehkhoda, M. Hood, The internal failure of rock samples subjected to pulsed water jet impacts, Int. J. Rock. Mech. Min. Sci. 66 (2014) 91-96.

[12]C. Ö. Karacan, W. P. Diamond, S. J. Schatzel, Numerical analysis of the influence of in-seam horizontal methane drainage boreholes on longwall face emission rates, Int. J. Coal. Geol. 72 (2007) 15-32.

[13]C. L. Tang, J. Pei, D. Hu, Experimental study on dynamic characteristics of self-excited oscillation pulsed jet, Adv. Mater. Res. 937 (2014) 624-631. 